\title{
The Role of Proximate and other Determinants in Ghana's Fertility Transition.
}

\author{
Samuel Nii Ardey Codjoe \\ Regional Institute for Population Studies \\ University of Ghana, Legon, Ghana. \\ Tel: 233-21-500274 or 233-244-365916 \\ e-mail: scodjoe@ug.edu.gh.
}

\begin{abstract}
Although studies have revealed some of the factors behind Ghana's fertility transition, much effort is still needed to explain the contribution to the transition of social factors such as beliefs, practices, customs, etc. Most of the studies have used macro-level data (mainly the Demographic and Health Surveys), and have therefore been unable to unravel in fine details the reasons at the micro level. The objective of this paper is to examine the role of proximate and other (mainly customs and practices) determinants in Ghana's fertility transition. Household data collected among 386 females aged between 15 and 49 years in March 2002 are used. Results show that certain cultural practices such as child fostering, and females perception of their husbands or male participating in a household chore (seen as the preserve of females in Ghana) i.e., cooking, among other factors, turn out to be significant predictors of children ever born. Further research is needed to ascertain the role of other factors, viz, females' perception of washing and babysitting by men, and the effect of practices such as badudwan (a female rewards the husband with a ram upon giving birth to the tenth child) on fertility.
\end{abstract}

Keywords: Proximate, Customs, Practices, Fertility determinants, Ghana 


\section{Introduction}

Numerous studies on fertility of sub-Saharan Africa prior to the 1990s found fertility rates to be very high. Several suggestions were advanced for this phenomenon. First, it was argued that the region has a cultural and anthropological peculiarity with respect to fertility and parenting (Caldwell and Caldwell, 1987). This view stresses the unique character of African values, institutions and practices which include easy access to marriage, a permissive attitude towards multiple partners, and a supportive kingship and household patterns which make children less of a burden to parents (IsiugoAbanihe, 1983). Another reason proffered for high sub-Sahara African fertility is the low socio-economic status of the region (World Bank, 1989). Yet another school of thought argues that most sub-Saharan African countries have peasant economies, with high demand for labour; given this situation of high demand for more hands to help in these peasant economies, high fertility is imperative in the region (Kamuzora, 1987). Others postulate that fertility levels were high in the sub-Saharan Africa region as a consequence low level of deliberate fertility control through contraception or induced abortion (Frank and McNicholl, 1987).

However, from the mid-1990s discussions on sub-Saharan Africa fertility has changed from the determinants of high fertility to the factors that have triggered the widespread fertility decline being observed in many countries. There is now a large volume of literature which suggests that sub-Saharan Africa has entered its fertility transition stage following fertility declines in Botswana, Kenya, Ghana, Republic of South Africa, Nigeria, Senegal, Lesotho, Swaziland, Namibia and Zimbabwe. Key fertility determinants responsible for these declines are increased use of modern contraception, improvements in female education and economic conditions, reduction in infant mortality rates, changing attitudes about large family sizes, and modernisation (Caldwell and Orubuloye, 1992; Vanderpost, 1992; Rutenberg and Diamond, 1993; Thomas and Muvandi, 1994; Robinson and Harbison, 1995; Onuoha and Timaeus, 1995; Agyei-Mensah, 1997 and Codjoe, 2004).

Several studies have attempted to provide reasons for the fertility transition currently taking place in Ghana (Agyei-Mensah and Aase, 1998; Gaisie, 2005; White et al., 2005; Codjoe, 2007). However, 
Samuel Nii Ardey Codjoe: The Role of Proximate and other Determinants in Ghana's Fertility Transition.

more work remains to be undertaken to explain the role of factors that have to do with social issues, beliefs, practices, customs, etc, in the transition. Also, most of the studies on fertility in Ghana have used macro-level (mainly Demographic and Health Survey) data, and therefore have been unable to unravel in fine-detail the reasons for the decline at the micro level. The objective of this paper is therefore to examine the role of proximate and other (mainly customs and practices) determinants in Ghana's fertility transition. Household data collected among 386 females aged between 15 and 49 years in March 2002 are used. The paper incorporates concepts from the proximate determinants (Bongaarts, 1978), epidemiological transition (Omran, 1971), neo-classical economic (Becker, 1960), structural (Davis, 1963) and ideational change (Lesthaeghe, 1983) models.

\section{Fertility transition in Ghana}

Before the middle of the 1960s, the issue of rapid population growth and high fertility were not seen to be major challenges confronting Ghana. The politicians were of the view that a strong correlation existed between the country's security and status at the international level, on the one hand, and the size of its population, on the other. This was a period of deficient birth statistics resulting from vital registration of extremely limited coverage. Also, methodologies used in censuses at the time did not meet guidelines provided by the United Nations.

In 1960, Ghana undertook its first modern population census and this brought with it a remarkable interest in fertility studies. Intensive field investigations were undertaken during the period and Ghana's fertility rate was reported to be 7.4 (Caldwell, 1965). It was also noted that there were little or no evidence of fertility differentials by social class; average number of children by females who had completed their reproductive life span was reported to be as high as 6 to 7 (Gaisie, 1968). Total fertility rate among the elite living in selected urban areas of Ghana in 1962 and 1963 was found to be 3.4 live births per 1000 women aged between 18 and 44 years (Caldwell, 1977).

With the overthrow of the first democratically elected government after political independence, the political leaders adopted a new attitude to the population issue. In 1967 Ghana became the first 
country in sub-Saharan Africa to be a signatory of the World Leaders' Declaration on Population (Ghana Government, 1969). The same year saw the founding of the Planned Parenthood Association of Ghana (PPAG), which was an affiliate of the International Planned Parenthood Federation (IPPF). Government showed some commitment in addressing the population and fertility issues at the time with the formulation of the first Ghana population policy in 1969. The formulation of the population policy in 1969 was immediately followed by the launching of a National Family Planning Programme in 1970. The main objective of the family planning programme was to address the problems that confronted the national population policy with regard to fertility issues.

A supplementary enquiry conducted after the 1970 Ghana population census, covering $5 \%$ of the total population put the fertility rate at 6.7. In 1979 the Ghana Fertility Survey (GFS), which was part of the World Fertility Survey (WFS), estimated Ghana's fertility rate at 6.5. Almost a decade after the GFS, the first Ghana Demographic and Health Survey (GDHS) was undertaken by the Ghana Statistical Service (GSS) in 1988. From this was emanated total fertility rate (TFR) of 6.4, showing a modest decline in fertility compared with the rates derived from GFS.

An evaluation of the 1979 GFS and the 1988 GDHS concluded that the GFS data yielded lower fertility than the GDHS for 1977-80, the period over which the results of the two surveys overlapped (Onuoha and Timaeus, 1995). Furthermore, comparison of estimates from each survey revealed that the level of fertility increased slightly during the period 1980 to 1988. Discrepancies found between fertility estimates in the GFS and GDHS within the same period gave a strong indication of some errors in the data from either one of the surveys or possibly in both. This disparity was attributed to underreporting of births in the GFS. It was further purported that the sampling frame or the sample drawn from it may have been biased in one or both surveys (Onuoha and Timaeus, 1995).

Between September 1993 and February 1994, Ghana undertook its second DHS, which revealed a significant decline in fertility levels in the country. TFR of 5.5 was reported, which represents a $14 \%$ decrease in fertility compared to the 1988 GDHS (Ghana Statistical Service, (GSS, 1994). Although TFR in Ghana fell by 14\% between 1988 
Samuel Nii Ardey Codjoe: The Role of Proximate and other Determinants in Ghana's Fertility Transition.

and 1993, declines were not experienced in all age groups. For instance, the percentage change in fertility among teenagers was very small (only about $4 \%$ ). Also, declines in age-specific fertility rates for females aged 20-29 were more pronounced. In 1998, TFR was reported as 4.5, a further decline in fertility from the 1993 survey (GSS, 1999). The most recent DHS conducted in Ghana in 2003 reported a TFR of 4.4, a slight decline from the 1998 survey (GSS et al., 2004).

The above demonstrates that the fertility transition in Ghana can be put in three stages, viz., the pre-transition period, which spans from about the 1960s to the end of the 1980s, the beginning of the transition, from the early 1990s, and the current phase of decisive transition, starting in the early 2000s.

\section{Study area}

Kassena-Nankana district is about $1,700 \mathrm{~km}^{2}$ in Northern Ghana, with a population of 149,491 in 2000 (GSS, 2002) and the EjuraSekyedumase district about $1,350 \mathrm{~km}^{2}$ with a population of 81,115 located in the middle belt of Ghana, are the two study areas used. The Kassena-Nankana district is $83 \%$ rural and the Ejura-Sekyedumase district is $67 \%$ rural. The Kassena-Nankana district is bounded by Burkina Faso to the North, Builsa district to the South, Bongo and Bolgatanga districts to the East, and Tumu district to the West. The Ejura-Sekyedumase district on the other hand, is bounded by the Atebubu district to the North, Afigya-Sekyere district to the South, Sekyere West district to the East and Offinso and Nkoranza districts to the West.

While the Kassena-Nankana district is mainly patrilineal and has a lot of its inhabitants belonging to the Islamic religion, Akans who are matrilineal and mainly Christians dominate the EjuraSekyedumase district. Furthermore, a study by Codjoe (2006) has shown that the Ejura-Sekyedumase district, which has a double farming season compared to Kassena-Nankana, which only has a single farming season, is wealthier (with regard to income earned from sale of farm produce, ownership of household consumer durables and livestock). For example, Ejura-Sekyedumase households earned on average almost twenty times more from the sale of farm produce than Kassena-Nankana households in 2000. The different 
beliefs, practices, customs, norms as well as socio-economic conditions in the two districts have implications for fertility and that is the main thrust of the discussions in this paper.

\section{Materials and methods}

The paper utilized data collected among 386 females aged between 15 and 49 years in March 2002 in the Kassena-Nankana (Northern Ghana) and Ejura Sekyedumase (Middle Belt) districts. A structured and open-ended questionnaire was administered by direct interview with the respondents, since the majority of the respondents had no formal education. The 2000 Ghana Population and Housing Census Report on communities was the basis for the selection of the communities used in the study. Most of the communities in both districts have very small population size, for instance, about $97 \%$ and $82 \%$ of all communities in the Ejura-Sekyedumase and KassenaNankana districts, respectively, had populations less than 800 people in 2000 (GSS, 2002).

The criterion of population size more than 800 was used to select the study locations, the idea being to use communities with relatively larger populations since they were more accessible. Twelve communities in the Ejura-Sekyedumase district qualified and were selected for the study. The communities include, Ejura, Sekyedumase, Anyinasu, Dromankuma, Frante, Kasei, Hiawoanwu, Aframso, Drobon, Nkwanta, Ashakoko and Bonyon. Forty communities met the selection in Kassena-Nankana district, out of which 12 communities were randomly selected to conform to the number in EjuraSekyedumase. They include Telania, Navrongo, Bonia, Kanania, Atibabisi, Yuwa Afarigabisi, Nabango, Paga, Mirigu, Badania, Manyoro and Janania. The simple random sampling procedure was used to select houses where the interviews were undertaken after a complete listing of all the houses in the communities. Twenty households were randomly selected from each of the communities.

With regard to analytical techniques, three multiple regression models for each district were separately modelled to assess the role of proximate and other determinants on fertility (children ever born). This enabled us firstly to isolate the net effects of both sets of proximate and other determinants on fertility, and then secondly, to 
Samuel Nii Ardey Codjoe: The Role of Proximate and other Determinants in Ghana's Fertility Transition.

examine the combined effects of both sets of determinants on fertility. The regression equations are specified below and the description of variables is presented in Table 1.

Proximate determinants model:

$\mathrm{CHDEB}=\alpha+\beta_{1} \mathrm{CONTR}+\beta_{2} \mathrm{EXCBR}+\beta_{3} \mathrm{MARST}+\beta_{4} \mathrm{AGEFS}+\varepsilon$

(1)

Other determinants model:

$\mathrm{CHDEB}=\alpha+\beta_{1}$ EDUST $+\beta_{2}$ MAJOC $+\beta_{3}$ COOKS $+\beta_{4}$ CFOST $+\beta_{5}$ CLOSS + $\beta_{6}$ RELGN $+\varepsilon$

The complete model:

$\mathrm{CHDEB}=\alpha+\beta_{1} \mathrm{CONTR}+\beta_{2} \mathrm{EXCBR}+\beta_{3} \mathrm{MARST}+\beta_{4} \mathrm{AGEFS}+\beta_{5} \mathrm{EDUST}+\ldots$ $\beta_{\mathrm{n}} \mathrm{RELGN}+\varepsilon$ 
Table 1: Description of variables and aggregation method used in the model

\begin{tabular}{|c|c|c|c|}
\hline $\begin{array}{c}\text { Abbrevi } \\
\text { ation }\end{array}$ & Variable & Description & Aggregation method/Response \\
\hline CHDEB & $\begin{array}{l}\text { Children ever } \\
\text { born }\end{array}$ & $\begin{array}{l}\text { Number of children (those who } \\
\text { survived for more than a day) } \\
\text { ever born - Dependent Variable }\end{array}$ & Absolute number \\
\hline CONTR & $\begin{array}{l}\text { Contraceptive } \\
\text { usage }\end{array}$ & $\begin{array}{l}\text { Female's ever use of any form of } \\
\text { contraception }\end{array}$ & $\begin{array}{ll}\text { 1. } & \text { Yes } \\
\text { 2. No }\end{array}$ \\
\hline EXCBR & Breastfeeding & $\begin{array}{l}\text { Breastfeeding practice of female } \\
\text { for last child }\end{array}$ & $\begin{array}{l}\text { 1. Exclusive breastfeeding } \\
\text { (for } 6 \text { months without any } \\
\text { food supplement } \\
\text { 2. Non-exclusive } \\
\text { breastfeeding (Food } \\
\text { supplements are added } \\
\text { before the sixth month) }\end{array}$ \\
\hline MARST & Marital status & Marital status of female & $\begin{array}{ll}\text { 1. } & \text { Married } \\
\text { 2. } & \text { Never married } \\
\text { 3. } & \text { Divorced } \\
\text { 4. } & \text { Separated } \\
\text { 5. } & \text { Widowed } \\
\end{array}$ \\
\hline AGEFS & First birth & Female's age at first birth & Absolute number \\
\hline EDUST & $\begin{array}{l}\text { Educational } \\
\text { status }\end{array}$ & Educational status of female & $\begin{array}{ll}\text { 1. } & \text { No schooling } \\
\text { 2. } & \text { Primary/basic } \\
\text { 3. } & \text { JSS/middle } \\
\text { 4. } & \text { SSS/ secondary }\end{array}$ \\
\hline
\end{tabular}




\begin{tabular}{|c|c|c|c|}
\hline & & & 5. Tertiary \\
\hline MAJOC & $\begin{array}{l}\text { Major } \\
\text { occupation }\end{array}$ & Major occupation of female & $\begin{array}{ll}\text { 1. Farming } \\
\text { 2. }\end{array}$ \\
\hline COOKS & Cooking & $\begin{array}{l}\text { Female approves of a man } \\
\text { cooking }\end{array}$ & $\begin{array}{ll}\text { 1. } & \text { Yes } \\
\text { 2. } & \text { No }\end{array}$ \\
\hline CFOST & $\begin{array}{l}\text { Child } \\
\text { Fosterage }\end{array}$ & $\begin{array}{l}\text { Any of the female's children is } \\
\text { living in fosterage }\end{array}$ & $\begin{array}{ll}\text { 1. } & \text { Yes } \\
\text { 2. No }\end{array}$ \\
\hline CLOSS & Loss of a child & Any child of female ever died & $\begin{array}{ll}\text { 1. Yes } \\
\text { 2. No }\end{array}$ \\
\hline RELGN & Religion & Religious affiliation & $\begin{array}{ll}\text { 1. } & \text { Christian } \\
\text { 2. Moslem } \\
\text { 3. Other }\end{array}$ \\
\hline
\end{tabular}




\section{Results and Discussions}

\section{Proximate determinants of fertility}

Table 2 shows that current use of contraceptives among the females was $25 \%$ in Kassena-Nankana and $28 \%$ in EjuraSekyedumase. The current use of contraceptives for all females in the Kassena-Nankana district is much higher than what pertains in the entire Upper East region (11.9\%) where it is located (GSS et al. 2004), and that of Ejura-Sekyedumase (28\%) district almost compares to the Ashanti region (29.7\%), the most demographically advanced region in Ghana. Also, the 25\% current contraceptive prevalence among females in Ghana, according to the 2003 GDHS, is slightly lower than what pertains in the Ejura-Sekyedumase district but exactly the same as the figure for the Kassena-Nankana district.

The differentials in the two districts could probably be accounted for by the location of Ejura-Sekedumase in southern part of Ghana, and consequently better access to family planning services compared to in Kassena-Nankana located in northern Ghana. In addition, the fact that the differential between the two districts is not very large could be attributed to the closeness of Kassena-Nankana to the Navrongo Research Centre, which has demonstrated to appreciable success over the years with respect to the provision of family planning services (Debpuur et al., 2002).

Table 2: Females by proximate fertility determinant and study area

\begin{tabular}{|c|c|c|c|}
\hline & $\begin{array}{l}\text { Kassena- } \\
\text { Nankana }\end{array}$ & $\begin{array}{c}\text { Ejura- } \\
\text { Sekyedumase }\end{array}$ & Ghana \\
\hline \multicolumn{4}{|l|}{ Proximate determinant } \\
\hline Currently use contraceptive (\%) & 25 & 28 & 25 \\
\hline Exclusively breastfed last child (\%) & 82 & 49 & 55 \\
\hline Currently married (\%) & 84 & 88 & 54 \\
\hline Median age at first birth (years) & 19.3 & 20.2 & 20.5 \\
\hline
\end{tabular}

Source: Fieldwork, 2002 and GSS et al., 2004.

The analysis also shows that $82 \%$ of the females in the Kassena-Nankana district exclusively breastfed their last child 
Samuel Nii Ardey Codjoe: The Role of Proximate and other Determinants in Ghana's Fertility Transition.

compared to $49 \%$ of the females in Ejura-Sekyedumase. While the figure for Kassena-Nankana is much higher than the national figure of $55 \%$, that of Ejura-Sekyedumase is slightly lower. This could be attributed among other things to the vigorous nutritional campaigns undertaken by the Navrongo Health Research Centre.

Furthermore, Table 2 shows that $84 \%$ and $88 \%$ of the females in the Kassena-Nankana and Ejura-Sekyedumse districts were, respectively, married at the time of the survey. Both figures are much higher than the national average of $54 \%$. This may be related to the predominantly rural nature of the two districts and proportions of females married normally are higher in rural communities. In addition, the median ages at first birth were 19.3 years and 20.2 years in Kassena-Nankana and Ejura-Sekyedumase, respectively. The median ages at first birth in both districts are slightly lower than the national figure of 20.5 years.

\section{Other determinants of fertility}

Table 3 shows that there were more females with no formal education in the Kassena-Nankana district (69\%) compared to females in the Ejura-Sekyedumase district (53\%). This could be attributed to the fact that there are more educational institutions in southern Ghana, compared to the north. The proportion of females with no formal schooling is higher for the two districts compared to the national figure of $37 \%$.

Table 3: Percentage of females by other fertility determinant and study area

\begin{tabular}{lccc}
\hline & $\begin{array}{c}\text { Kassena- } \\
\text { Nankana }\end{array}$ & $\begin{array}{c}\text { Ejura- } \\
\text { Sekyedumase }\end{array}$ & Ghana \\
\cline { 1 - 2 } Other determinant & 69 & 53 & 37 \\
No formal schooling & 74 & 83 & 36 \\
Occupation (Farmer) & 76 & 54 & - \\
Approve of husband cooking & 18 & 22 & - \\
Have a child living in fosterage & 15 & 5 & - \\
Experienced the loss of a child & 60 & 83 & 77 \\
Religion (Christian) & & & \\
\hline
\end{tabular}

Source: Fieldwork, 2002 and GSS et al., 2004. 
In addition, the analysis shows that the majority of females in both geographic areas, i.e., $74 \%$ and $83 \%$ in the Kassena-Nankana and Ejura-Sekyedumase districts, respectively, were farmers. Also, approval rate for cooking by husbands was higher in KassenaNankana (76\%) compared to Ejura-Sekyedumase (54\%). This may suggest that Kassena-Nankana females have more modern attitudes than their Ejura-Sekyedumase district counterparts.

A higher proportion of females in the Ejura-Sekyedumase district $(22 \%)$ compared to Kassena-Nankana (18\%) had at least a child living in fosterage. This may be due to the matrilineal system operating in the Ejura-Sekyedumase district, which encourages close ties between kith and kin. This is different from the patrilineal system practised in the Kassena-Nankana district, which may not promote such close links among clan members.

Furthermore, Table 3 shows that the proportion of females who have experienced the loss of a child is three times higher in the Kassena-Nankana (15\%) district compared to the Ejura-Sekyedumase $(5 \%)$ district, probably due to the low socio-economic status of the Kassena-Nankana district compared to Ejura-Sekyedumase. Finally, there are more Christians in Ejura-Sekyedumase (83\%) compared to Kassena-Nankana (60\%). This is due to the fact that southern Ghana is predominantly Christian and the northern Ghana has a large Moslem population.

Females in the Ejura-Sekyedumase district, which is wealthier, were expected to have more modernised attitudes than their counterparts in the Kassena-Nankana district. However, all the variables used to assess the role of ideational change on fertility are in favour of females in the Kassena-Nankana district. They had fewer children living in fosterage and higher proportions of them approved of their husbands cooking. However, with regard to socio-economic conditions, females in the Ejura-Sekyedumase district were more educated and had experienced fewer child deaths although higher proportions of them were engaged in farming. As far as proximate determinants of fertility are concerned, females in the KassenaNankana district gave birth earlier, fewer of them were currently married, exclusively breastfed for longer periods, and practised less contraception. 
Samuel Nii Ardey Codjoe: The Role of Proximate and other Determinants in Ghana's Fertility Transition.

\section{Multivariate analysis}

Results of the multiple regression models for the proximate and other fertility determinants for the two districts are shown in Tables 4. Age at first birth is a statistically significant proximate determinant of fertility common to both geographical areas. However, a female's current marital status is peculiar to the Ejura-Sekyedumase district. Age at first birth is inversely related to children ever born in both districts. Thus, an increase of one year in the age at first birth reduced the number of children ever born by 0.18 and 0.16 in the Kassena-Nankana and Ejura-Sekyedumase districts, respectively. Finally, although not significant, contraceptive use had a decreasing effect on fertility in Kassena-Nankana and exclusive breastfeeding decreased fertility in both geographical areas. 
Table 4: Parameters of multiple regression models explaining the proximate and other determinants of fertility in the Kassena-Nankana and Ejura-Sekyedumase districts of Ghana, 2000

\begin{tabular}{|c|c|c|c|c|c|c|}
\hline & \multicolumn{3}{|c|}{ Kassena-Nankana district } & \multicolumn{3}{|c|}{ Ejura-Sekyedumase district } \\
\hline & $\mathrm{B}$ & SE & $\mathrm{t}$ & B & SE & $\mathrm{t}$ \\
\hline \multicolumn{7}{|c|}{ Proximate determinant } \\
\hline CONTR & -0.144 & 0.335 & -0.430 & 0.090 & 0.342 & 0.289 \\
\hline EXCBR & -0.462 & 0.398 & -1.162 & -0.091 & 0.315 & -0.288 \\
\hline MARST & -0.197 & 0.178 & -1.106 & $-0.568^{* * *}$ & 0.196 & -2.895 \\
\hline AGEFS & $-0.183^{* * *}$ & 0.041 & -4.463 & $-0.157^{* * *}$ & 0.041 & -3.818 \\
\hline Constant & $7.812^{* * *}$ & 0.876 & 8.913 & $7.791^{* * *}$ & 0.916 & 8.507 \\
\hline $\mathrm{R}^{2}$ & 0.153 & & & 0.122 & & \\
\hline Adjusted R2 & 0.127 & & & 0.100 & & \\
\hline $\mathrm{F}$ & $5.964^{* * *}$ & & & $5.503^{* * *}$ & & \\
\hline \multicolumn{7}{|c|}{ Other determinant } \\
\hline EDUST & $-0.679 * * *$ & 0.172 & -3.955 & -0.154 & 0.209 & -0.736 \\
\hline MAJOC & 0.122 & 0.110 & 1.106 & -0.041 & 0.181 & -0.240 \\
\hline COOKS & $0.813^{* *}$ & 0.333 & 2.437 & -0.325 & 0.333 & -0.975 \\
\hline CFOST & $0.870^{* *}$ & 0.360 & 2.419 & 0.676 & 0.420 & 1.608 \\
\hline CLOSS & $1.267^{* * *}$ & 0.399 & 3.174 & $1.163^{*}$ & 0.650 & 1.790 \\
\hline RELGN & 0.001 & 0.157 & 0.002 & 0.317 & 0.253 & 1.253 \\
\hline Constant & $2.897^{* * *}$ & 0.653 & 4.437 & $4.596^{* * *}$ & 0.774 & 5.937 \\
\hline $\mathrm{R}^{2}$ & 0.240 & & & 0.065 & & \\
\hline Adjusted R2 & 0.203 & & & 0.026 & & \\
\hline $\mathrm{F}$ & $6.485^{\star * *}$ & & & 8.349 & & \\
\hline $\mathrm{N}$ & 192 & & & 194 & & \\
\hline
\end{tabular}


Samuel Nii Ardey Codjoe: The Role of Proximate and other Determinants in Ghana's Fertility Transition.

The model for other determinants of fertility shows that while the experience of the loss of a child predicted number of children ever born by females in both districts, educational status of the female, approval of cooking by husband, and child fosterage is peculiar to the Kassena-Nankana district. Furthermore, experience of the loss of a child, however, increased number of children ever born in both geographic settings. This confirms the fact that experience of the death of a child often prompts couples to replace the lost child aiding high fertility.

Educational status of women, approval of cooking by husband, and child fosterage are the other predictors of children ever born in the Kassena-Nankana district. Educational status has an inverse relationship with children ever born, implying that more educated women give birth to fewer children compared to their counterparts with no formal schooling. This confirms the assertion by Caldwell and Caldwell (1987) that education is a significant factor with respect to fertility, with an inverse relationship with fertility. This is a positive development with regard to the fertility transition due to the fact that northern Ghana still has relatively high fertility rates. If educational levels can be improved, it would go a long way to curtail the high fertility rates found in that part of the country.

This study envisaged that women who approved of their husbands cooking would have more modern attitudes, thus have lower fertility, and vice versa. This hypothesis is confirmed in EjuraSekyedumase but not in Kassena-Nankana. High fertility was expected amongst females with high child fosterage, since the economic burden for taking care of their children becomes lessened. The results confirm this expectation, as an additional child living in fosterage increased number of children ever born by 0.9 in the Kassena-Nankana district.

When both sets of fertility determinants are combined in a single model, age at first birth and educational status are statistically significant in both districts (see Table 5). However, major occupation, approval of male cooking and child loss experience proved to be predictors of fertility in Kassena-Nankana, while marital status and child fosterage are fertility predictors in Ejura-Sekyedumase. 
The analysis shows that age at first birth and educational status of females are significant predictors of fertility in both the separate and combined models and in each of the districts. In both instances, they carry the expected sign, i.e., inversely related to fertility. Child loss experience is also a significant predictor of fertility in both models and increased fertility by values ranging from 0.9 to 1.3 and this can be considered to be quite high. Furthermore, child fosterage is a predictor of fertility in Kassena-Nankana in the separate model and Ejura-Sekyedumase in the combined model. In both instances, it has an increasing effect on fertility by 0.9 children. Finally, the variable used to assess modernised attitudes, i.e., approval of cooking by men was significant in Kassena-Nankana in both the separate and combined models.

Table 5: Parameters of multiple regression models explaining the determinants of fertility in the Kassena-Nankana and EjuraSekyedumase districts of Ghana, 2000

\begin{tabular}{|c|c|c|c|c|c|c|}
\hline & \multicolumn{3}{|c|}{$\begin{array}{c}\begin{array}{c}\text { Kassena-Nankana } \\
\text { district }\end{array} \\
\end{array}$} & \multicolumn{3}{|c|}{$\begin{array}{c}\text { Ejura-Sekyedumase } \\
\text { district }\end{array}$} \\
\hline & B & SE & $\mathbf{t}$ & B & SE & $\mathbf{t}$ \\
\hline \multicolumn{7}{|l|}{$\begin{array}{l}\text { Fertility } \\
\text { determinant }\end{array}$} \\
\hline CONTR & 0.283 & 0.377 & 0.751 & 0.376 & 0.339 & 1.108 \\
\hline EXCBR & -0.251 & 0.420 & -0.598 & -0.137 & 0.316 & -0.436 \\
\hline MARST & -0.109 & 0.188 & -0.580 & $-0.564^{* * *}$ & 0.209 & -2.694 \\
\hline AGEFS & $-0.160^{* * *}$ & 0.045 & -3.590 & $-0.165^{* * *}$ & 0.038 & -4.379 \\
\hline EDUST & $-0.573^{* * *}$ & 0.185 & -3.103 & $-0.340^{*}$ & 0.188 & -1.805 \\
\hline MAJOC & $0.242^{*}$ & 0.125 & 1.937 & -0.225 & 0.440 & -0.510 \\
\hline COOKS & $0.676^{*}$ & 0.372 & 1.816 & -0.137 & 0.317 & -0.433 \\
\hline CFOST & 0.635 & 0.430 & 1.478 & $0.923^{* *}$ & 0.371 & 2.487 \\
\hline CLOSS & $0.860^{*}$ & 0.473 & 1.816 & -0.294 & 0.572 & -0.515 \\
\hline RELGN & -0.001 & 0.198 & -0.007 & 0.253 & 0.254 & 0.996 \\
\hline Constant & $6.488^{* * *}$ & 1.229 & 5.280 & $8.363^{* * *}$ & 1.131 & 7.393 \\
\hline $\mathrm{R}^{2}$ & 0.340 & & & 0.257 & & \\
\hline Adjusted R² & 0.274 & & & 0.198 & & \\
\hline $\mathrm{F}$ & $5.108^{* * *}$ & & & $4.354^{* * *}$ & & \\
\hline $\mathrm{N}$ & 192 & & & 194 & & \\
\hline
\end{tabular}


Samuel Nii Ardey Codjoe: The Role of Proximate and other Determinants in Ghana's Fertility Transition.

\section{Conclusion}

This paper has attempted to unravel the proximate and other (social issues, beliefs, practices, customs) factors accounting for Ghana's fertility transition at the household level. This was done because most of the studies on Ghana's transition have used macrolevel data, which makes it impossible to ascertain the roles of social issues, beliefs, practices, customs, etc., in the transition. Although a very small sample population is used, what this paper has revealed is, firstly, that certain cultural practices such as child fostering, and women's perception of their husbands or men participating in a household chore (such as cooking seen as the preserve of females in Ghana), among other factors, are significant predictors of children ever born.

Secondly, median age at first birth in these districts compares favourably to the national average and it tends to be having decreasing effects on fertility. This is a very positive development and the Government of Ghana is urged to do more through sensitisation campaigns to further increase the age at first birth. Linked to this is the fact that proportions of females with no formal education in these districts are still high. Because education has a decreasing effect on fertility in both districts, the promotion of girl child education, which is ongoing in the country, should be intensified in these districts, especially Kassena-Nankana.

Thirdly, proportion of females who exclusively breastfed their children is relatively high, particularly in the Kassena-Nankana district. This is also a very positive finding due to the fact that exclusive breastfeeding decreased fertility in both districts. It is recommended that more nutritional campaigns should be undertaken especially in the Ejura-Sekyedumase district and other parts of the country to encourage mothers to breastfeed their babies without any food supplements at least for the first six months.

Fourthly, one surprising feature of the Ghanaian fertility transition is that modern contraception usage has not kept pace with the observed fertility decline and this has been evidently shown in this paper. Contraceptive use among females in these districts is still 
very low. Low patronage of modern contraceptives especially in the rural areas is one of the factors that could be a stumbling block to future fertility decline in Ghana. The Government is therefore urged to reposition family planning, which has suffered lately as a result of the HIV/AIDS pandemic, which seems to be receiving all the attention.

Fifthly, this study has shown that the proportion of females who had experienced the loss of a child is quite low in the two districts. However, the study shows that this variable increased fertility, because the experience of the death of a child often prompts couples to replace the lost child. Since infant mortality rate appears to be stabilising in Ghana, the Government is urged to continue and possibly intensify its drive to further bring down infant mortality rate. Child fosterage was found to increase fertility especially in KassenaNankana. This is a cultural practice which also has a form of economic underpinnings, and therefore, cannot be easily eroded. Yet, it is believed that when families are in the position to economically take care of their children, this practice will gradually fade away.

Finally, further research is needed in other parts of the country experiencing the transition, to see whether this finding is consistent with those areas. Further research could also include other factors such as females' perception of men washing and babysitting, and the effect of practices such as badudwan (a female rewards her husband with a ram upon giving birth to the tenth child) on fertility.

\section{References}

Agyei-Mensah, S.1997. Fertility Change in a Time and Space Perspective: Lessons from Three Ghanaian Settlements. Unpublished $\mathrm{PhD}$ Dissertation, Geography Institute, Norges TekniskNaturvitenskapelige Universitet, Trondheim.

Agyei-Mensah, S. and Aase, A. (1998): Patterns of Fertility Change in Ghana: A Time and Space Perspective, Geografiska Annaler 80B(4): 202213. 
Samuel Nii Ardey Codjoe: The Role of Proximate and other Determinants in Ghana's Fertility Transition.

Becker, G. 1960. An Economic Analysis of Fertility. In: Demographic and Economic Change in Developed Countries, NBER Conference Series, No. 11 Princeton: Princeton University Press.

Bongaarts, J. 1978. A Framework for Analysing the Proximate Determinants of Fertility, Population and Development Review, 4 (1): 105132.

Caldwell, J.C. 1965. Extended Family Obligations and Education: A Study of an Aspect of Demographic Transition among Ghanaian University Students, Population Studies, 19 (2): 183-199.

Caldwell, J.C. 1977. Population Growth and Family Change in Africa: The New Urban Elite in Ghana. London: C. Hurst and Company.

Caldwell, J.C. and Caldwell, P. 1987. The Cultural Context of High Fertility in Sub-Saharan Africa, Population and Development Review, 13 (3): 409-437.

Caldwell, J.C., Caldwell, P. and Orubuloye, I. 1992. Fertility Decline in Africa. A New Type of Transition? Population and Development Review, 18 (2):211-242.

Caldwell, J.C., Caldwell, P. and Orubuloye, I. 1993. The South African Fertility Decline. Population and Development Review, 19 (2): 225-262.

Cochrane, S. 1979. Fertility and Education: What Do We Really Know? Baltimore: John Hopkins University Press.

Codjoe, S.N.A. 2004. Cohort Analysis of Fertility Change among Females in Two Agro-ecological Zones of Ghana, Research Review (New Series), 20 (2): 11-21.

Codjoe, S.N.A. 2006. Population Growth and Agricultural Land Use in Two Agro-ecological Zones of Ghana, 1960-2010, International Journal of Environmental Studies, 63 (5): 645-661.

Codjoe, S.N.A. 2007. Varying Effect of Fertility Determinants among Migrant and Indigenous Females in the Transitional Agro-ecological Zone of Ghana, Geografiska Annaler, 89B (1): 23-37. 
Davis, K. 1963. The Theory of Change and Response in Modern Demographic History, Population Index, 29: 345-366.

Frank, O. and McNicholl, G. 1987. An Interpretation of Fertility and Population Policy in Kenya, Population and Development Review, 13 (2):209-243.

Gaisie, S.K. 1968. Some Aspects of Fertility Studies in Ghana. In: Caldwell JC and Okonjo C. (Eds.). The Population of Tropical Africa. Longmans.

Gaisie, S.K. 2005. Fertility Trend in Ghana. African Population Studies, 20(2):1-24.

Ghana Government. 1969. Studies in Family Planning. Official Policy Statement. August.

Ghana Statistical Service. 1994. Ghana Demographic and Health Survey, 1993. Demographic and Health Surveys Macro International Inc.

Ghana Statistical Service. 1999. Ghana Demographic and Health Survey, 1998. Demographic and Health Surveys Macro International Inc.

Ghana Statistical Service. 2002. 2000 Population and Housing Census. Summary Report on Final Results. Accra: Medialite Co. Ltd.

Ghana Statistical Service (GSS), Noguchi Memorial Institute for Medical Research (NMIMR) and ORC Macro. 2004. Ghana Demographic and Health Survey, 2003. Calverton, Maryland: GSS, NMIMR, and ORC Macro.

Isiugo-Abanihe, U.C. 1983. Child Fostering in West Africa: Prevalence, Determinants and Demographic Consequences (Ghana, Liberia, Sierra Leone, Nigeria). Ph.D. Thesis, University of Pennsylvania.

Kamuzora, C.L. 1987. Survival Strategy: The Historical and Economic Roots of an African High Fertility Culture. Cultural Roots of African Fertility regimes. In: Proceedings of the Ife Conference. Feb 25-March 1. 
Samuel Nii Ardey Codjoe: The Role of Proximate and other Determinants in Ghana's Fertility Transition.

Lesthaeghe, R. 1983. A Century of Demographic and Cultural Change in Western Europe. An Exploration of Underlying Dimensions, Population and Development Review, (3): 411-435.

Omran, AR. 1971. The Epidemiology Transition Theory: A Theory of the Epidemiology of Population Change, Milbank Memorial Fund Quarterly, 49: 6-47.

Onuoha, N.C. and Timaeus, I.M. 1995. Has a Fertility Transition Begun in West Africa? Journal of International Development, 7(1): 93-116.

Robinson, W.C. and Harbinson, S.F. 1995. The Fertility Decline in Kenya. Journal of International Development, 7(1): 81-92.

Rutenberg, N. and Diamond, I. 1993. Fertility in Botswana: The Recent Decline and Future Prospects, Demography, 30(2): 143-157.

Thomas, D. and Muvandi, I. 1994. The Demographic Transition in Southern Africa: Another Look at the Evidence from Botswana and Zimbabwe, Demography, 31(2): 177-199.

Vanderpost, P. 1992. Regional Patterns of Fertility Transition in Botswana, Geography, 335 (77): 102-122.

White, M.J., Tagoe, E., Stiff, C., Adazu, K. and Smith, D.J. 2005. Urbanization and the fertility transition in Ghana, Population Research and Policy Review, 24: 59-83.

World Bank. 1986. Population Growth and Policies in Sub-Saharan Africa. Washington DC. 